\title{
Search for methylamine in high mass hot cores ${ }^{\star}$
}

\author{
N. F. W. Ligterink ${ }^{1,2}$, E. D. Tenenbaum ${ }^{1}$, and E. F. van Dishoeck $^{1,3}$ \\ ${ }^{1}$ Leiden Observatory, Leiden University, PO Box 9513, 2300 RA Leiden, The Netherlands \\ e-mail: ligterink@strw.leidenuniv.nl \\ 2 Raymond and Beverly Sackler Laboratory for Astrophysics, Leiden Observatory, Leiden University, PO Box 9513, \\ 2300 RA Leiden, The Netherlands \\ 3 Max-Planck Institut für Extraterrestrische Physik (MPE), Giessenbackstr. 1, 85748 Garching, Germany
}

Received 21 August 2014 / Accepted 18 December 2014

\begin{abstract}
Aims. We aim to detect methylamine, $\mathrm{CH}_{3} \mathrm{NH}_{2}$, in a variety of hot cores and use it as a test for the importance of photon-induced chemistry in ice mantles and mobility of radicals. Specifically, $\mathrm{CH}_{3} \mathrm{NH}_{2}$ cannot be formed from atom addition to $\mathrm{CO}$ whereas other $\mathrm{NH}_{2}$-containing molecules such as formamide, $\mathrm{NH}_{2} \mathrm{CHO}$, can.

Methods. Submillimeter spectra of several massive hot core regions were taken with the James Clerk Maxwell Telescope (JCMT). Abundances are determined with the rotational diagram method where possible.

Results. Methylamine is not detected, giving upper limit column densities between $1.9-6.4 \times 10^{16} \mathrm{~cm}^{-2}$ for source sizes corresponding to the $100 \mathrm{~K}$ envelope radius. Combined with previously obtained JCMT data analysed in the same way, abundance ratios of $\mathrm{CH}_{3} \mathrm{NH}_{2}, \mathrm{NH}_{2} \mathrm{CHO}$ and $\mathrm{CH}_{3} \mathrm{CN}$ with respect to each other and to $\mathrm{CH}_{3} \mathrm{OH}$ are determined. These ratios are compared with Sagittarius $\mathrm{B} 2$ observations, where all species are detected, and to hot core models.

Conclusions. The observed ratios suggest that both methylamine and formamide are overproduced by up to an order of magnitude in hot core models. Acetonitrile is however underproduced. The proposed chemical schemes leading to these molecules are discussed and reactions that need further laboratory studies are identified. The upper limits obtained in this paper can be used to guide future observations, especially with ALMA.
\end{abstract}

Key words. astrochemistry - line: identification - methods: observational - stars: formation - ISM: abundances - ISM: molecules

\section{Introduction}

Complex organic molecules are thought to be formed primarily on dust grains in dense cores, see reviews by Herbst \& van Dishoeck (2009) and Caselli \& Ceccarelli (2012). Before the onset of star formation, the atomic and molecular reservoir is contained in large dark clouds. Due to the high densities $\left(\geq 10^{4} \mathrm{~cm}^{-3}\right)$ and low temperatures $(10 \mathrm{~K})$ reached in these environments, gas-phase species will freeze out on sub-micron sized grains forming ice mantles on timescales shorter than the lifetime of the cloud. It is here that atoms and molecules can potentially react with each other to form the zeroth order ice species like ammonia, methane, water and methanol. UV radiation interacts with these ice mantles by dissociating molecules to produce radicals and by photodesorbing species back to the gas phase. If these radicals are sufficiently mobile, they can find each other on the grain and react to form even more complex first generation (organic) species (Garrod \& Herbst 2006). However, it is not entirely clear if UV radiation is essential to form these complex molecules or whether they can also be formed just by thermal processing and atom bombardment of solid $\mathrm{CO}$ with $\mathrm{C}, \mathrm{N}$ and O atoms (Tielens \& Charnley 1997).

In this context methylamine, $\mathrm{CH}_{3} \mathrm{NH}_{2}$, is a particularly interesting molecule, since its formation is hypothesised by Garrod et al. (2008) to be completely dependent on radicals produced

* Appendices are available in electronic form at http: //wwW . aanda.org by UV photons, and is one of the few molecules that can definitely not be produced in the routes starting from solid CO:

$$
\begin{aligned}
& \mathrm{CH}_{4}+\mathrm{h} v \rightarrow \mathrm{CH}_{3}^{\bullet}+\mathrm{H} \\
& \mathrm{NH}_{3}+\mathrm{h} v \rightarrow \mathrm{NH}_{2}^{\bullet}+\mathrm{H} \\
& \mathrm{CH}_{3}^{\bullet}+\mathrm{NH}_{2}^{\bullet} \rightarrow \mathrm{CH}_{3} \mathrm{NH}_{2} .
\end{aligned}
$$

These radicals can form in the ice mantles in the dark cloud or in the protostellar phase through cosmic-ray induced photons and/or UV photons from the protostar. After gravitational collapse of the cloud and formation of a protostar, the dust around it will start to warm up. The increased temperature will cause the radicals to become mobile on the grains and react with each other, forming methylamine. Further heating will evaporate the formed methylamine from the grain and raise its gas-phase abundance.

Another interesting amine-containing molecule is formamide, $\mathrm{NH}_{2} \mathrm{CHO}$. This is so far the most abundantly observed amine-containing molecule (e.g., Halfen et al. 2011; Bisschop et al. 2007), making it an interesting molecule to compare with other amines like methylamine. In contrast with $\mathrm{CH}_{3} \mathrm{NH}_{2}$, this molecule can possibly be produced by reactions of $\mathrm{H}$ and $\mathrm{N}$ with solid $\mathrm{CO}$. The comparison of the abundances of these two species could potentially give more information about the relative importance of UV-induced versus thermal grain surface reactions.

Hot cores are particularly well-suited to study methylamine. These high mass star-forming regions reach high temperatures 
Table 1. Source list and source parameters.

\begin{tabular}{|c|c|c|c|c|c|c|c|c|c|c|}
\hline Source & $\begin{array}{r}\text { RA } \\
\text { J2000 }\end{array}$ & $\begin{array}{r}\text { Dec } \\
\text { J2000 }\end{array}$ & $\begin{array}{r}\theta_{\mathrm{S}}^{a} \\
\mathrm{AU}\end{array}$ & $\begin{array}{r}\theta_{\mathrm{B}}^{a} \\
\mathrm{AU}\end{array}$ & $\begin{array}{l}L^{a} \\
L_{\odot}\end{array}$ & $\begin{array}{r}d^{a} \\
(\mathrm{kpc})\end{array}$ & $\begin{array}{r}V_{\mathrm{LSR}} \\
\left(\mathrm{km} \mathrm{s}^{-1}\right)\end{array}$ & $\begin{array}{r}\Delta V \\
\left(\mathrm{~km} \mathrm{~s}^{-1}\right)\end{array}$ & $\begin{array}{r}\delta v \\
\left(\mathrm{~km} \mathrm{~s}^{-1}\right)\end{array}$ & $\begin{array}{r}\mathrm{rms} \\
(\mathrm{mK})\end{array}$ \\
\hline AFGL 2591 & $20: 29: 24.60$ & $+40: 11: 18.9$ & 1800 & 21000 & $2.0 \mathrm{E}+05$ & 3.3 & -5.5 & 4.0 & 1.28 & 10 \\
\hline G24.78 & $18: 36: 12.60$ & $-07: 12: 11.0$ & 13000 & 162000 & $7.9 \mathrm{E}+05$ & 7.7 & 111.0 & 6.3 & 1.28 & 9 \\
\hline $\mathrm{G} 31.41+0.31$ & $18: 47: 34.33$ & $-01: 12: 46.5$ & 7840 & 166000 & $2.6 \mathrm{E}+05$ & 7.9 & 98.7 & 7.3 & 1.28 & 7 \\
\hline G75.78 & $20: 21: 44.10$ & $+37: 26: 40.0$ & 5600 & 86100 & $1.9 \mathrm{E}+05$ & 4.1 & -0.04 & 5.6 & 1.28 & 9 \\
\hline IRAS 18089-1732 & $18: 11: 51.40$ & $-17: 31: 28.5$ & 2750 & 49000 & $3.2 \mathrm{E}+04$ & 2.3 & 33.8 & 4.5 & 1.28 & 9 \\
\hline IRAS $20126+4104$ & $20: 14: 26.40$ & $+41: 13: 32.5$ & 1753 & 34400 & $1.3 \mathrm{E}+04$ & 1.6 & -3.8 & 6.0 & 1.28 & 10 \\
\hline NGC 7538 IRS1 & $23: 13: 45.40$ & $+61: 28: 12.0$ & 4900 & 58800 & $1.3 \mathrm{E}+05$ & 2.8 & -57.4 & 4.0 & 1.28 & 10 \\
\hline $\mathrm{W} 3\left(\mathrm{H}_{2} \mathrm{O}\right)$ & 02:27:04.60 & $+61: 52: 26.0$ & 2400 & 42000 & $2.0 \mathrm{E}+04$ & 2.0 & -46.4 & 5.0 & 1.28 & 11 \\
\hline W 33A & $18: 14: 38.90$ & $-17: 52: 04.0$ & 4500 & 84000 & $1.0 \mathrm{E}+05$ & 4.0 & 37.5 & 4.9 & 1.28 & 11 \\
\hline
\end{tabular}

Notes. ${ }^{(a)}$ Data for AFGL 2591 taken from Rygl et al. (2012). Other data taken from Bisschop et al. (2007) and Isokoski et al. (2013).

between 100 to $300 \mathrm{~K}$ and are known for their rich complex organic chemistry (Walmsley 1992; van Dishoeck \& Blake 1998; Tielens \& Charnley 1997; Ehrenfreund \& Charnley 2000; Caselli \& Ceccarelli 2012). The ice covered grains move inwards to the protostar and will heat up. When sufficient temperatures are reached, molecules will start to desorb depending on their respective binding energies. Less abundant molecules mixed with water ice will desorb together with water around $100 \mathrm{~K}$.

Previous detections of methylamine have all been made toward the galactic center. Kaifu et al. (1974) first detected $\mathrm{CH}_{3} \mathrm{NH}_{2}$ in Sagittarius B2 and Orion A. Later that same year Fourikis et al. (1974) reported the detection of methylamine in the same sources, but with a different telescope. Much more sensitive surveys by Turner (1991), Nummelin et al. (2000), Halfen et al. (2013), Belloche et al. (2013) and Neill et al. (2014) also all detected methylamine lines toward Sgr B2, with typical inferred abundance ratios with respect to $\mathrm{NH}_{2} \mathrm{CHO}$ between 0.5 to 3 . No detections of methylamine have been reported in sensitive surveys with modern detectors toward Orion, however (Blake et al. 1987; Turner 1991; Sutton et al. 1995; Schilke et al. 1997; Crockett et al. 2014).

To study the importance of UV processing of ice-covered dust grains, we present the results of searches for methylamine in a number of hot cores (see Table 1). These results are combined and compared with data from Bisschop et al. (2007) and Isokoski et al. (2013), which were taken toward the same hot cores with the same telescope and analysis method and include detections of $\mathrm{NH}_{2} \mathrm{CHO}$ and other nitrogen-containing species. In Sect. 2 the observational details are given, followed by the analysis method in Sect. 3. Section 4 summarizes all the results of our analysis and these are discussed in Sect. 5. Finally conclusions are drawn in Sect. 6.

\section{Observations}

Observations were performed with the James Clerk Maxwell Telescope $(\mathrm{JCMT})^{1}$ on the sources listed in Table 1 between July 2010 and August 2011. The sources were selected based on their particularly rich chemistry, being isolated, having narrow line widths to prevent line confusion and on their relatively nearby distance (Bisschop et al. 2007; Fontani et al. 2007; Rathborne et al. 2008; Isokoski et al. 2013).

\footnotetext{
1 The James Clerk Maxwell Telescope is operated by the Joint Astronomy Centre on behalf of the Science and Technology Facilities Council of the United Kingdom, the National Research Council of Canada, and (until 31 March 2013) the Netherlands Organisation for Scientific Research.
}

Table 2. Methylamine transitions observed in this study.

\begin{tabular}{ccrcr}
\hline \hline Transition & $\begin{array}{c}\text { Freq. } \\
(\mathrm{MHz})\end{array}$ & $\begin{array}{r}E_{\mathrm{up}} \\
(\mathrm{K})\end{array}$ & $\begin{array}{c}A \\
\left(\mathrm{~s}^{-1}\right)\end{array}$ & $g_{\text {up }}$ \\
\hline $4_{2} \rightarrow 4_{1}{ }^{a}$ & 229310.298 & 36.9 & $1.32 \mathrm{E}-05$ & 108 \\
$7_{2} \rightarrow 7_{1}{ }^{a}$ & 229452.603 & 75.5 & $5.88 \mathrm{E}-06$ & 60 \\
$8_{2} \rightarrow 8_{1}{ }^{b}$ & 235735.037 & 92.8 & $6.13 \mathrm{E}-05$ & 204 \\
$6_{2} \rightarrow 6_{1}{ }^{a}$ & 236408.788 & 60.8 & $5.94 \mathrm{E}-05$ & 52 \\
$2_{2} \rightarrow 2_{1}{ }^{a}$ & 237143.530 & 22.0 & $3.82 \mathrm{E}-05$ & 60 \\
$10_{2} \rightarrow 10_{1}{ }^{c}$ & 260293.536 & 132.7 & $2.26 \mathrm{E}-05$ & 52 \\
\hline
\end{tabular}

Notes. Data from JPL database for molecular spectroscopy. ${ }^{(a)}$ Transition observed in all sources. ${ }^{(b)}$ Only observed in $\mathrm{W} 3\left(\mathrm{H}_{2} \mathrm{O}\right)$. (c) Only observed in $\mathrm{W} 3\left(\mathrm{H}_{2} \mathrm{O}\right)$ and NGC 7538 IRS1.

Nummelin et al. (1998) detected methylamine emission lines between 218 to $263 \mathrm{GHz}$ toward Sgr B2N. Therefore the RxA3 front-end double side band receiver, functioning between 210 to $276 \mathrm{GHz}$, was chosen to observe the hot cores. The 250 and $1000 \mathrm{MHz}$ wide back-end ACSIS configurations were used. A number of methylamine transitions covering a range of excitation energies were selected in this frequency range based on high Einstein $A$ coefficients and lack of line confusion (Table 2). However, not all transitions were observed for all sources. The $235735 \mathrm{MHz}$ transition was only recorded for $\mathrm{W} 3\left(\mathrm{H}_{2} \mathrm{O}\right)$ and the $260293 \mathrm{MHz}$ transition only toward $\mathrm{W} 3\left(\mathrm{H}_{2} \mathrm{O}\right)$ and NGC 7538 IRS1.

Because double side band spectra were obtained, our spectra contain transitions from two different frequency regimes superposed. To disentangle lines from the two side bands, each source was observed twice with an $8 \mathrm{MHz}$ shift in the local oscillator setting between the two observations. This allows each transition to be uniquely assigned to either of the two side bands.

In the $230 \mathrm{GHz}$ band, the JCMT has a beam size $\left(\theta_{\mathrm{B}}\right)$ of $20-21^{\prime \prime}$. Spectra were scaled from the antenna temperature scale, $T_{\mathrm{A}}^{*}$, to main beam temperature, $T_{\mathrm{MB}}$, by using the main beam efficiency of 0.69 at $230 \mathrm{GHz}$. Integration times were such that $T_{\text {rms }}$ is generally better than $10 \mathrm{mK}$ for data binned to $1.3 \mathrm{~km} \mathrm{~s}^{-1}$ velocity bins. Noise levels were improved by adding the shifted spectra together in a narrow frequency region around the $\mathrm{CH}_{3} \mathrm{NH}_{2}$ lines, effectively doubling the integration time.

\section{Data analysis}

To analyse the data, exactly the same method as described by Bisschop et al. (2007) and Isokoski et al. (2013) was used. 
It will be shortly reiterated here. The hot core spectra corrected for source velocity were analysed with the "Weeds" extension (Maret et al. 2011) of the Continuum and Line Analysis Single-dish Software $\left(\mathrm{CLASS}^{2}\right)$ coupled with the Jet Propulsion Laboratory $\left(\mathrm{JPL}^{3}\right)$ database for molecular spectroscopy (Pickett et al. 1998). Focus was on identifying the transitions of methylamine listed in Table 2, but other lines in the spectra were measured as well (see Table A.1). After each positive identification the integrated main-beam temperature, $\int T_{\mathrm{MB}} \mathrm{d} V$, was determined by Gaussian fitting of the line. From the integrated main-beam intensity the column density $N_{\text {up }}$ and thus the beamaveraged total column density $N_{\mathrm{T}}$ could be determined, assuming Local Thermodynamic Equilibrium (LTE) at a single excitation temperature $T_{\text {rot }}$ :

$$
\frac{3 k \int T_{\mathrm{MB}} \mathrm{d} V}{8 \pi^{3} v \mu^{2} S}=\frac{N_{\text {up }}}{g_{\text {up }}}=\frac{N_{T}}{Q\left(T_{\text {rot }}\right)} \mathrm{e}^{-E_{\text {up }} / T_{\text {rot }}}
$$

where $g_{\text {up }}$ is the level degeneracy, $k$ the Boltzmann constant, $v$ the transition frequency, $\mu$ the dipole moment and $S$ the line strength. $Q\left(T_{\text {rot }}\right)$ is the rotational partition function and $E_{\text {up }}$ is the upper state energy in Kelvin.

In case of a non-detection, $3 \sigma$ upper limits were determined from the root mean square (rms) of the base line of the spectra in combination with the velocity resolution $\delta v$ and line width $\Delta V$ :

$\sigma=1.2 \sqrt{\delta v \Delta V} \cdot \mathrm{rms}$

$\Delta V$ is estimated from other transitions (see Table 1) in the spectra, for example from the nearby $\mathrm{H}_{2} \mathrm{CS} 7_{1} \rightarrow 6_{1}$ transition, and assumed to be the same for all transitions in the spectral range. A telescope flux calibration error of $20 \%$ is taken into account in the 1.2 factor. The $3 \sigma$ value is then used in the same way as the main-beam intensity of detected lines to obtain the upper limit on the total column density through Eq. (1).

Since no rotational temperature can be determined for a nondetection, this has to be estimated. In the models of Garrod et al. (2008) the peak abundance temperatures for methylamine range from 117 to $124 \mathrm{~K}$ depending on the model used. Öberg (2009) determined that methylamine forms in $\mathrm{CH}_{4} / \mathrm{NH}_{3} \mathrm{UV}$ irradiation experiments and sublimates at $120 \mathrm{~K}$. There is a small difference between laboratory and hot core desorption temperatures, because of the pressure difference between the two. Also, if $\mathrm{CH}_{3} \mathrm{NH}_{2}$ is embedded in water ice the desorption temperature will probably be limited to roughly $100 \mathrm{~K}$, when water desorbs in space. Therefore $T_{\text {rot }}$ is assumed to be $120 \mathrm{~K}$ when methylamine lines could not be identified, but the effects of lower and higher rotation temperatures are explored as well.

Correction for beam dilution is done in the same way as Bisschop et al. (2007):

$\eta_{\mathrm{B} F}=\frac{\theta_{\mathrm{S}}^{2}}{\theta_{\mathrm{S}}^{2}+\theta_{\mathrm{B}}^{2}}$

resulting in the source-averaged column density:

$N_{\mathrm{S}}=\frac{N_{T}}{\eta_{\mathrm{B} F}}$.

The beam diameter $\theta_{\mathrm{B}}$ is set at $21^{\prime \prime}$. For the source diameter, $\theta_{\mathrm{S}}$, values have been taken from Bisschop et al. (2007) and Isokoski et al. (2013) and constitute the area where the temperature is

\footnotetext{
2 http://wWW.iram.fr/IRAMFR/GILDAS

3 http://spec.jpl.nasa.gov
}

$100 \mathrm{~K}$ or higher and hot gas-phase molecules are present. Both beam and source diameters are listed in AU in Table 1. Using the CASSIS line analysis software ${ }^{4}$ it was verified that the sourceaveraged column densities are still small enough that the observed lines are optically thin.

\section{Results and comparison with astrochemical models}

\section{1. $\mathrm{CH}_{3} \mathrm{NH}_{2}$ limits}

Figure 1 presents examples of spectra obtained for our sources, whereas Fig. A.2 shows the $2_{2}-2_{1}$ line in all sources. In general, no transitions of $\mathrm{CH}_{3} \mathrm{NH}_{2}$ are detected. Only one possible methylamine transition is identified in $\mathrm{G} 31.41+0.31$ coincident with the $6_{2} \rightarrow 6_{1}$ line at $236408 \mathrm{MHz}$, with an integrated intensity of $0.44 \mathrm{~K} \mathrm{~km} \mathrm{~s}^{-1}$. Following the procedure summarized in Sect. 3, a column density of $3.4 \times 10^{17} \mathrm{~cm}^{-2}$ is inferred from this line assuming $T_{\text {rot }}=120 \mathrm{~K}$. However, modelling of the spectrum shows that the other targeted $\mathrm{CH}_{3} \mathrm{NH}_{2}$ lines, $4_{2} \rightarrow 4_{1}$ and $2_{2} \rightarrow 2_{1}$, should have comparable or even higher intensities if this identification is correct (Fig. A.1). The $8_{2} \rightarrow 8_{1}$ line should be readily detected but was not observed toward G31.41+0.31. This makes it unlikely that the detected feature belongs to methylamine, since we would expect to see at least two other $\mathrm{CH}_{3} \mathrm{NH}_{2}$ transitions in our spectrum.

In Fig. 2 upper limit column densities of the six investigated transitions of methylamine are plotted versus rotational temperature taking a typical $3 \sigma=0.100 \mathrm{~K} \mathrm{~km} \mathrm{~s}^{-1}$. At $120 \mathrm{~K}$ the $8_{2} \rightarrow 8_{1}$, $235735 \mathrm{MHz}$ transition gives the lowest limits on the column densities, see Fig. 2. However, since this particular transition was only included in the observations for one source, the second most sensitive transition at $120 \mathrm{~K}, 2_{2} \rightarrow 2_{1}$, will be used (see Fig. A.2 for a blow-up of this particular spectral region in all investigated sources). All following molecular ratios are based on $\mathrm{CH}_{3} \mathrm{NH}_{2}$ column densities obtained from this line, assuming $T_{\text {rot }}=120 \mathrm{~K}$. The corresponding upper limits are presented in Table 3.

\subsection{Abundance ratio comparison}

Combined with $\mathrm{NH}_{2} \mathrm{CHO}$ and $\mathrm{CH}_{3} \mathrm{OH}$ column densities from Bisschop et al. (2007) and Isokoski et al. (2013) derived in the same way, abundance ratios for methylamine and formamide with respect to each other and to methanol are calculated. These ratios are listed in Table 3. Methanol is chosen as a reference since it is the most readily observed complex organic molecule. Its disadvantage is that some of the transitions have high optical depth and that a cold component may be present (Isokoski et al. 2013), but this is circumvented by only taking the warm methanol column density derived from optically thin lines. Abundances relative to methanol rather than $\mathrm{H}_{2}$ are preferred since the $\mathrm{H}_{2}$ column depends on extrapolation of dust models to smaller scales than actually observed (Bisschop et al. 2007). Another point that needs to be taken into account is that the models of Garrod et al. (2008) do show a slight overproduction of $\mathrm{CH}_{3} \mathrm{OH}$, which could influence the comparison between the ratios. Overall, the abundance ratios are estimated to be accurate to a factor of a few.

It should be noted that methylamine and formamide have significantly different dipole moments (1.31 and 3.73 Debye respectively) and could therefore be excited in different ways.

\footnotetext{
4 CASSIS has been developed by IRAP-UPS/CNRS (http:// cassis.irap.omp.eu).
} 


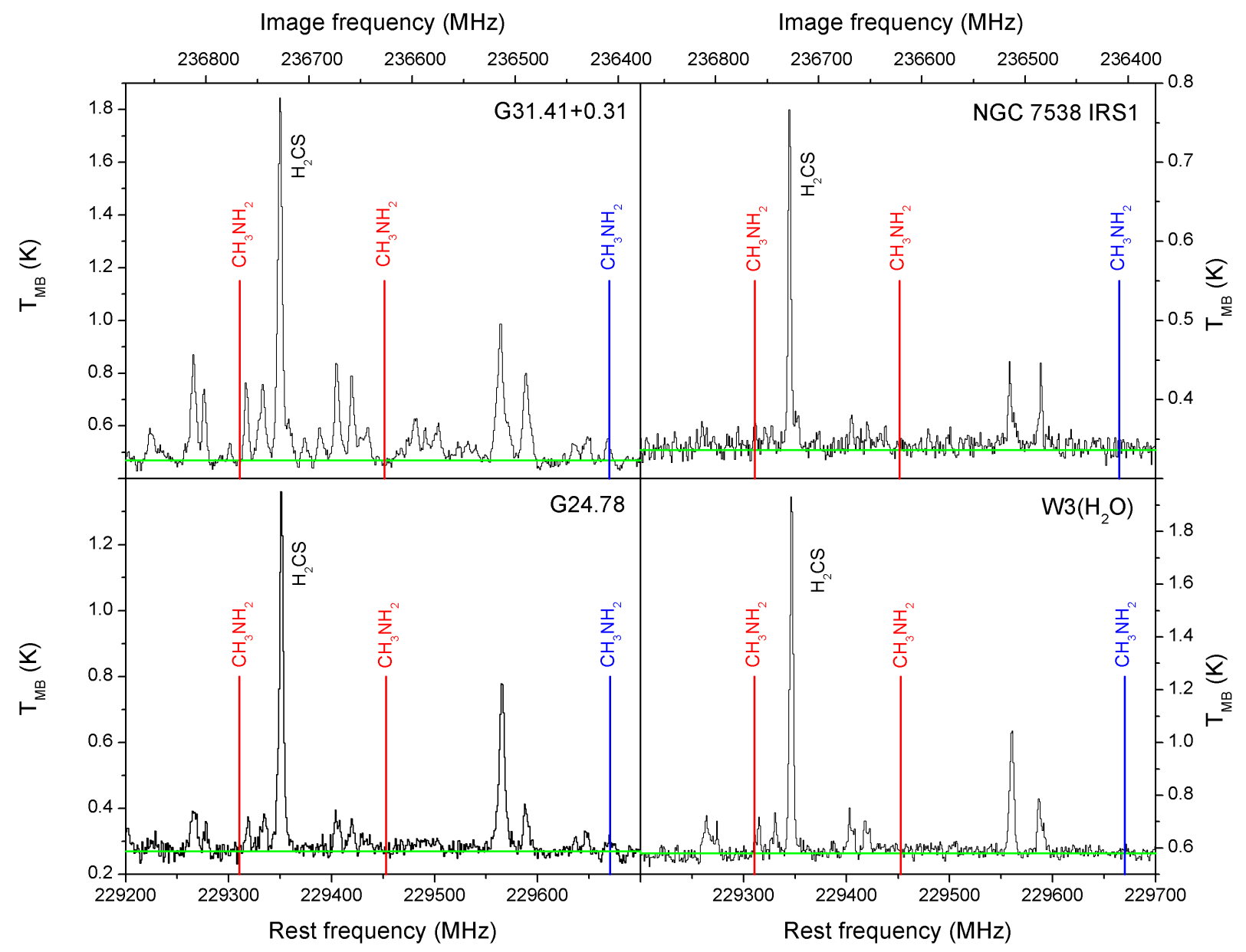

Fig. 1. JCMT spectra of the massive hot cores G31.41+0.31, G24.75, NGC 7538 IRS1 and W3( $\left.\mathrm{H}_{2} \mathrm{O}\right)$. The 229310 and $229452 \mathrm{MHz}$ transitions in the lower sideband are indicated in red and that at $236408 \mathrm{MHz}$ in the upper sideband in blue. In green is the baseline, obtained by fitting line free portions of the spectrum. In all spectra the $\mathrm{H}_{2} \mathrm{CS} 7_{1} \rightarrow 6_{1}$ transition at $236726 \mathrm{MHz}$ is fitted to determine the typical linewidth in the sources, as listed in Table 1.

Formamide has a larger critical density than methylamine, so the situation could arise where the critical density is not reached for formamide or even both molecules. The corresponding excitation temperatures will then be lower. In particular, the situation in which the critical density is not reached for formamide but is for methylamine, could affect the inferred ratios. As can be seen from Fig. 2, if $T_{\text {rot }}$ drops from 120 to $50 \mathrm{~K}$, the column density drops by a factor of a few, depending on transition. If $T_{\text {rot }}$ were $120 \mathrm{~K}$ for methylamine but $50 \mathrm{~K}$ for formamide, the observed column density of formamide would be lower than that listed here and thus result in a higher $\mathrm{CH}_{3} \mathrm{NH}_{2} / \mathrm{NH}_{2} \mathrm{CHO}$ ratio. We note, however, that there is no observational evidence that $T_{\text {rot }}$ is systematically lower than $100 \mathrm{~K}$ for formamide (Bisschop et al. 2007).

Table 3 includes the observational results toward Sgr B2, the only source where methylamine is firmly detected, from Turner (1991), Belloche et al. (2013) and Neill et al. (2014). These results, obtained over the course of more than two decades, agree well with each other within the estimated uncertainties due to slightly different adopted source sizes. Nummelin et al. (2000) also detect methylamine in their Sgr B2 survey but find a surprisingly small beam filling factor and consequently very large column density compared with most other complex organic molecules. If their beam filling factor for $\mathrm{CH}_{3} \mathrm{NH}_{2}$ is taken to be the same as for $\mathrm{NH}_{2} \mathrm{CHO}$, the Nummelin et al. (2000) ratios are more in line with those derived by Turner (1991),
Belloche et al. (2013) and Neill et al. (2014). The non-detections of methylamine toward the chemically rich and well studied Orion hot core imply abundance limits that are at least a factor of 5 lower than for Sgr B2 (Neill et al. 2014; Crockett et al. 2014).

Table 3 also contains the model results from Garrod et al. (2008), who present three hot core models which differ from each other by their warm-up timescale from 10 to $200 \mathrm{~K}$. The timescales for $\mathrm{F}$ (ast), M(edium) and $\mathrm{S}$ (low) are $5 \times 10^{4}, 2 \times 10^{5}$ and $1 \times 10^{6}$ years, respectively, and start after the cold collapse phase. In the slow models more time is spent in the warm-up phase where radicals are mobile. Values used in this comparison are taken from the so-called reduced ice composition, where cold phase methane and methanol abundances were modified to match observations of these ices toward W33A, NGC 7538 IRS9 and Sgr A*, see Gibb et al. (2000). Another comparison can be made with the gas-phase abundances in protoplanetary disk models of Walsh et al. (2014) which have similar or higher densities and temperatures as in protostellar cores. Their ratios range from $7.2 \times 10^{-1}$ to $6.5 \times 10^{-2}$ for $\mathrm{CH}_{3} \mathrm{NH}_{2} / \mathrm{CH}_{3} \mathrm{OH}$, $4.2 \times 10^{-1}$ to 1.5 for $\mathrm{CH}_{3} \mathrm{NH}_{2} / \mathrm{NH}_{2} \mathrm{CHO}$ and 1.7 to $8.8 \times 10^{-2}$ for the $\mathrm{NH}_{2} \mathrm{CHO} / \mathrm{CH}_{3} \mathrm{OH}$. These ratios are close to the predicted values of Garrod et al. (2008) listed in Table 3, which may be partly due to using the same surface-chemistry network.

From Table 3 several trends become apparent for our results. The $\mathrm{CH}_{3} \mathrm{NH}_{2} / \mathrm{NH}_{2} \mathrm{CHO}$ limits lie about an order of magnitude 
N. F. W. Ligterink et al.: Search for methylamine in high mass hot cores

Table 3. Upper limit column densities and abundance ratios for methylamine.

\begin{tabular}{|c|c|c|c|c|c|}
\hline Source & $\begin{array}{l}N_{\mathrm{S}, \mathrm{CH}_{3} \mathrm{NH}_{2}} \\
\mathrm{~cm}^{-2}\end{array}$ & $\mathrm{CH}_{3} \mathrm{NH}_{2} / \mathrm{NH}_{2} \mathrm{CHO}$ & $\mathrm{CH}_{3} \mathrm{NH}_{2} / \mathrm{CH}_{3} \mathrm{OH}$ & $\mathrm{NH}_{2} \mathrm{CHO} / \mathrm{CH}_{3} \mathrm{OH}$ & $\mathrm{NH}_{2} \mathrm{CHO}_{\text {upper }} / \mathrm{CH}_{3} \mathrm{OH}$ \\
\hline Model F & & 1.1 & 3.4E-02 & 3.1E-02 & $3.1 \mathrm{E}-02$ \\
\hline Model M & & 1.7 & $1.0 \mathrm{E}-01$ & 7.3E-02 & 7.3E-02 \\
\hline Model S & & 1.3 & $1.3 \mathrm{E}-01$ & $1.0 \mathrm{E}-01$ & $1.0 \mathrm{E}-01$ \\
\hline AFGL 2591 & $<1.9 \mathrm{E}+16$ & - & - & $<3.9 \mathrm{E}-01$ & - \\
\hline $\mathrm{G} 24.78$ & $<2.4 \mathrm{E}+16$ & $<3.3 \mathrm{E}+01$ & $<8.5 \mathrm{E}-02$ & $2.6 \mathrm{E}-03$ & $9.0 \mathrm{E}-04$ \\
\hline $\mathrm{G} 31.41+0.31$ & $<5.8 \mathrm{E}+16$ & $<2.8 \mathrm{E}+01$ & $<4.9 \mathrm{E}-02$ & $1.8 \mathrm{E}-03$ & $3.8 \mathrm{E}-03$ \\
\hline G75.78 & $<3.5 \mathrm{E}+16$ & $<1.7 \mathrm{E}+02$ & $<3.1 \mathrm{E}-01$ & $1.8 \mathrm{E}-03$ & $2.6 \mathrm{E}-02$ \\
\hline IRAS 18089-1732 & $<4.2 \mathrm{E}+16$ & $<5.0 \mathrm{E}+01$ & $<1.9 \mathrm{E}-01$ & $3.8 \mathrm{E}-03$ & 7.9E-03 \\
\hline IRAS $20126+4104$ & $<6.4 \mathrm{E}+16$ & - & $<2.2$ & - & - \\
\hline NGC 7538 IRS 1 & $<2.0 \mathrm{E}+16$ & $<3.5 \mathrm{E}+01$ & $<1.8 \mathrm{E}-01$ & $4.8 \mathrm{E}-03$ & $2.1 \mathrm{E}-04$ \\
\hline $\mathrm{W} 3\left(\mathrm{H}_{2} \mathrm{O}\right)$ & $<5.0 \mathrm{E}+16$ & $<3.9 \mathrm{E}+01$ & $<5.0 \mathrm{E}-02$ & $1.3 \mathrm{E}-03$ & $6.4 \mathrm{E}-04$ \\
\hline $\mathrm{W} 3\left(\mathrm{H}_{2} \mathrm{O}\right)^{*}$ & $<1.7 \mathrm{E}+16$ & $<1.3 \mathrm{E}+01$ & $<1.7 \mathrm{E}-02$ & $1.3 \mathrm{E}-03$ & $6.4 \mathrm{E}-04$ \\
\hline W 33A & $<5.7 \mathrm{E}+16$ & $<2.7 \mathrm{E}+01$ & $<2.9 \mathrm{E}-01$ & $1.1 \mathrm{E}-02$ & $4.6 \mathrm{E}-03$ \\
\hline $\mathrm{Sgr} \mathrm{B} 2^{a}$ & $1.2 \mathrm{E}+14$ & $5.7 \mathrm{E}-01$ & $1.7 \mathrm{E}-02$ & $1.3 \mathrm{E}-02$ & \\
\hline $\operatorname{Sgr} \mathrm{B} 2(\mathrm{M})^{b}$ & $4.5 \mathrm{E}+16$ & 3.2 & $1.7 \mathrm{E}-02$ & $5.2 \mathrm{E}-03$ & \\
\hline $\operatorname{Sgr} \mathrm{B} 2(\mathrm{~N})^{b}$ & $6.0 \mathrm{E}+17$ & 4.3E-01 & $3.3 \mathrm{E}-02$ & $7.8 \mathrm{E}-02$ & \\
\hline $\operatorname{Sgr} \mathrm{B} 2(\mathrm{~N})^{c}$ & $5.0 \mathrm{E}+17$ & 2.1 & $1.0 \mathrm{E}-01$ & $4.8 \mathrm{E}-02$ & \\
\hline Orion Compact Ridge ${ }^{d}$ & - & - & - & $1.6 \mathrm{E}-03$ & \\
\hline
\end{tabular}

Notes. Column densities for the assumed source size and upper limit abundance ratios for methylamine, derived from the $2_{2}-2_{1}$ line assuming $T_{\text {rot }}=120 \mathrm{~K}$. The values for $\mathrm{NH}_{2} \mathrm{CHO}$ and $\mathrm{CH}_{3} \mathrm{OH}$ where taken from Bisschop et al. (2007) and Isokoski et al. (2013). The upper limits of $\mathrm{NH}_{2} \mathrm{CHO}$ were determined by our own re-analysis of the Bisschop et al. (2007) data and taken from the appendix of Isokoski et al. (2013). ${ }^{(*)}$ Column density calculated for the $8_{2}-8_{1}$ line.

References. ${ }^{(a)}$ Turner (1991), beam sizes between 65" and 107", assuming no beam dilution; ${ }^{(b)}$ Belloche et al. (2013), beam sizes between $25^{\prime \prime}$ and $30^{\prime \prime}$, assuming a $3^{\prime \prime}$ source size for $(\mathrm{N})$ and $5^{\prime \prime}$ source size for $(\mathrm{M}) ;{ }^{(c)}$ Neill et al. (2014), beam sizes between 10" and 40", assuming source size of 2.5"; and ${ }^{(d)}$ Crockett et al. (2014) beam sizes between 44" and 11" and assuming a 10" size of the Compact Ridge.

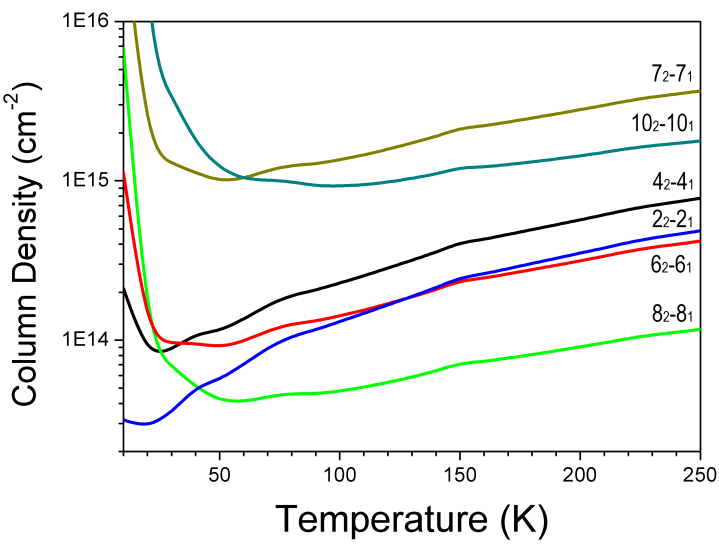

Fig. 2. Column densities for the six methylamine transitions plotted versus temperature. This plot is made for a $3 \sigma$ limit of $0.1 \mathrm{~K} \mathrm{~km} \mathrm{~s}^{-1}$, as found for $\mathrm{W} 3\left(\mathrm{H}_{2} \mathrm{O}\right)$. This figure demonstrates that the $8_{2}-8_{1}$ transition (green) gives the most sensitive limits on column density for the relevant range of excitation temperatures in hot cores, when observed. The other five transitions $\left(4_{2} \rightarrow 4_{1}\right.$, black; $72 \rightarrow 7_{1}$, gold; $10_{2} \rightarrow 10_{1}$, cyan; $2_{2} \rightarrow 2_{1}$, blue and $6_{2} \rightarrow 6_{1}$, red) clearly imply higher column densities. Only below $40 \mathrm{~K}$ does the $2_{2} \rightarrow 2_{1}$ line give lower column density limits.

above model values whereas the $\mathrm{CH}_{3} \mathrm{NH}_{2} / \mathrm{CH}_{3} \mathrm{OH}$ limit approximately matches with theoretical predictions. Because the observed values are actually $3 \sigma$ upper limits, this suggests that models overproduce $\mathrm{CH}_{3} \mathrm{NH}_{2}$. For the sources with the most stringent limits, such as $\mathrm{G} 31.41+0.31$ and the $8_{2}-8_{1}$ line in W3 $\left(\mathrm{H}_{2} \mathrm{O}\right)$, the $\mathrm{CH}_{3} \mathrm{NH}_{2} / \mathrm{CH}_{3} \mathrm{OH}$ limits are comparable or even lower than the abundance ratios for Sgr B2. The third ratio, $\mathrm{NH}_{2} \mathrm{CHO} / \mathrm{CH}_{3} \mathrm{OH}$, is also found to be lower than the models by up to one order of magnitude.
Close inspection of the Bisschop et al. (2007) data shows that the $\mathrm{NH}_{2} \mathrm{CHO}$ column densities may have larger uncertainties than quoted in their figures and tables. We have therefore re-analysed all $\mathrm{NH}_{2} \mathrm{CHO}$ data from that paper taking larger uncertainties into account. In general, this leads to lower $\mathrm{NH}_{2} \mathrm{CHO}$ column densities. Even using the upper limits from this reanalysis as well as those from Isokoski et al. (2013) (which were obtained with generous error bars), the $\mathrm{NH}_{2} \mathrm{CHO}_{\text {upper }} / \mathrm{CH}_{3} \mathrm{OH}$ ratios are significantly lower than the models. This suggests that both the methylamine and formamide abundances are too high in the models.

The SgrB2 detections tend to have lower $\mathrm{CH}_{3} \mathrm{NH}_{2} /$ $\mathrm{NH}_{2} \mathrm{CHO}$ and $\mathrm{CH}_{3} \mathrm{NH}_{2} / \mathrm{CH}_{3} \mathrm{OH}$ ratios than our upper limits and are also somewhat below the models, but generally do not differ more than a factor of a few. The Sgr B2 $\mathrm{NH}_{2} \mathrm{CHO} / \mathrm{CH}_{3} \mathrm{OH}$ ratios are also closer to the models results, at least for the faster models. However, the Orion Compact Ridge $\mathrm{NH}_{2} \mathrm{CHO} / \mathrm{CH}_{3} \mathrm{OH}$ value from Crockett et al. (2014) is comparable to that found for our sources and clearly lower than the models. Further observations are needed to determine to what extent Sgr B2 is a special case.

To further elucidate the differences between theory and our and the Sgr B2 observations, an additional analysis was made of the $\mathrm{CH}_{3} \mathrm{NH}_{2} / \mathrm{CH}_{3} \mathrm{CN}$ ratio. These results are listed in Table 4. Acetonitrile is produced in the gas-phase, but more abundantly on grains: an important route to its formation is via $\mathrm{CH}_{3}^{\bullet}+$ $\mathrm{CN}^{\bullet} \rightarrow \mathrm{CH}_{3} \mathrm{CN}$, according to Garrod et al. (2008). This would mean that both molecules compete for the methyl radical on the surface, thus relating the two molecules.

Our observed ratios involving $\mathrm{CH}_{3} \mathrm{CN}$ are clearly at odds with the theoretical predictions. The observed $\mathrm{CH}_{3} \mathrm{NH}_{2} / \mathrm{CH}_{3} \mathrm{CN}$ ratios are in most cases an order of magnitude lower than theory and approach the observed ratios for Sgr B2. However, 
Table 4. Upper limit column densities and abundance ratios for methylamine.

\begin{tabular}{|c|c|c|}
\hline Source & $\mathrm{CH}_{3} \mathrm{NH}_{2} / \mathrm{CH}_{3} \mathrm{CN}$ & $\mathrm{CH}_{3} \mathrm{CN} / \mathrm{CH}_{3} \mathrm{OH}$ \\
\hline Model F & $5.5 \mathrm{E}+01$ & 6.3E-04 \\
\hline Model M & $3.8 \mathrm{E}+01$ & $2.6 \mathrm{E}-03$ \\
\hline Model S & $1.5 \mathrm{E}+01$ & $8.6 \mathrm{E}-03$ \\
\hline AFGL 2591 & $<5.3$ & $<7.5 \mathrm{E}-02$ \\
\hline G24.78 & $<5.1 \mathrm{E}-01$ & $2.1 \mathrm{E}-01$ \\
\hline $\mathrm{G} 31.41+0.31$ & $<3.6$ & $5.9 \mathrm{E}-02^{*}$ \\
\hline G75.78 & $<1.9 \mathrm{E}+01$ & $1.6 \mathrm{E}-02$ \\
\hline IRAS 18089-1732 & $<8.9$ & $1.1 \mathrm{E}-02^{*}$ \\
\hline IRAS 20126+4104 & $<4.3 \mathrm{E}+01$ & $5.2 \mathrm{E}-02$ \\
\hline NGC 7538 IRS1 & $<2.5$ & $6.8 \mathrm{E}-02$ \\
\hline $\mathrm{W} 3\left(\mathrm{H}_{2} \mathrm{O}\right)$ & $<7.2$ & $7.0 \mathrm{E}-03$ \\
\hline W 33A & $<2.1$ & $1.4 \mathrm{E}-01$ \\
\hline Sgr B2 $2^{a}$ & 1.2 & $1.5 \mathrm{E}-02$ \\
\hline Sgr B2(N) $)^{b}$ & $3.0 \mathrm{E}-01$ & $1.1 \mathrm{E}-01$ \\
\hline Sgr B2(M) ${ }^{b}$ & $2.5 \mathrm{E}-01$ & $6.7 \mathrm{E}-02$ \\
\hline Sgr B2(N) ${ }^{c}$ & $5.9 \mathrm{E}+01$ & $1.7 \mathrm{E}-02$ \\
\hline Orion Compact Ridge ${ }^{d}$ & - & $1.1 \mathrm{E}-02$ \\
\hline
\end{tabular}

Notes. Abundance ratios for methylamine. The values for $\mathrm{CH}_{3} \mathrm{OH}$ and $\mathrm{CH}_{3} \mathrm{CN}$ were taken from Bisschop et al. (2007) and Isokoski et al. (2013). ${ }^{(*)}$ Ratio derived from optically thin ${ }^{13} \mathrm{C}$ isotope.

References. ${ }^{(a)}$ Turner (1991); ${ }^{(b)}$ Belloche et al. (2013); ${ }^{(c)}$ Neill et al. (2014); and ${ }^{(d)}$ Crockett et al. (2014) .

the observed $\mathrm{CH}_{3} \mathrm{CN} / \mathrm{CH}_{3} \mathrm{OH}$ ratios are 1-2 orders of magnitude higher than theoretical predictions. Both these cases point to $\mathrm{CH}_{3} \mathrm{CN}$ being underproduced in the models.

Finally, abundance ratios, with some notable exceptions, do not vary more than an order of magnitude between different sources, as also found by Bisschop et al. (2007) for other species.

\section{Discussion}

Despite a significant number of succesfully identified molecules (see Table A.1, for examples of $\mathrm{W} 3\left(\mathrm{H}_{2} \mathrm{O}\right)$ and $\mathrm{G} 31.41+0.31$ ), only upper limits were found for methylamine in the various hot cores, limiting the conclusions that can be drawn. Nevertheless, trends are seen in our abundance ratios. The results suggest that theoretically predicted abundances for both methylamine and formamide are too high. In contrast, acetonitrile is found to be underproduced in the models. In the following, each of these species is discussed individually.

\section{1. $\mathrm{CH}_{3} \mathrm{NH}_{2}$}

Garrod et al. (2008) suggest that methylamine is primarily formed by grain-surface chemistry using UV to create the $\mathrm{CH}_{3}$ and $\mathrm{NH}_{2}$ radicals from photodissociation of primarily $\mathrm{CH}_{4}$ and $\mathrm{NH}_{3}$. Perhaps the amount of UV processing is overestimated in these models. An alternative route is hydrogen atom addition to solid HCN, proposed by Theule et al. (2011) and found to lead to both $\mathrm{CH}_{2} \mathrm{NH}$ (methanimine) and $\mathrm{CH}_{3} \mathrm{NH}_{2}$. Walsh et al. (2014) find in their models that methylamine is indeed efficiently formed on grains at $10 \mathrm{~K}$ by atom addition reactions to solid $\mathrm{CH}_{2} \mathrm{NH}$. Burgdorf et al. (2010) have detected HCN ice on Triton, but so far no detection of solid $\mathrm{HCN}$ has been made in the interstellar medium (ISM). Methanimine is actually readily observed in the gas-phase (Turner 1991; Nummelin et al. 1998; Belloche et al. 2013) so the presence of both species makes the $\mathrm{H}$-atom addition scheme probable. However, Halfen et al. (2013) detect $\mathrm{CH}_{2} \mathrm{NH}$ in $\mathrm{Sgr} \mathrm{B} 2(\mathrm{~N})$ at a rotational temperature of $44 \mathrm{~K}$, which is distinctly colder than the $159 \mathrm{~K}$ observed for $\mathrm{CH}_{3} \mathrm{NH}_{2}$, suggesting that the two molecules may not co-exist. An alternative route would therefore be to form these molecules by two different gas-phase reaction pathways $\left(\mathrm{CH}^{\bullet}(\mathrm{g})+\mathrm{NH}_{3}(\mathrm{~g})\right.$ $\rightarrow \mathrm{CH}_{2} \mathrm{NH}+\mathrm{H}$ and $\left.\mathrm{CH}_{3}^{\bullet}(\mathrm{g})+\mathrm{NH}_{3}(\mathrm{~g}) \rightarrow \mathrm{CH}_{3} \mathrm{NH}_{2}+\mathrm{H}\right)$, with $\mathrm{CH}$ being present primarily in the colder outer envelope and $\mathrm{CH}_{3}$ in the warmer center. Further modeling is needed to determine whether these gas-phase reactions can reproduce the observed abundances quantitatively.

\section{2. $\mathrm{NH}_{2} \mathrm{CHO}$}

Formamide also appears to be overproduced in the hot core model. Since Garrod et al. (2008) use both gas-phase, radical and atom addition reactions to form formamide, it is difficult to pin down where the discrepancies could come from. It is known that $\mathrm{NH}_{2} \mathrm{CHO}$ is formed in CO: $\mathrm{NH}_{3}$ mixtures after UV and electron irradiation (Grim et al. 1989; Demyk et al. 1998; Jones et al. 2011) and it has also been proposed that it can form from $\mathrm{H}$ - and $\mathrm{N}$-atom addition to solid CO (Tielens \& Charnley 1997). Gasphase formation from $\mathrm{CO}$ and $\mathrm{NH}_{3}$ is viable as well (Hubbard et al. 1975), although these experiments were conducted under high-pressure conditions, not the low pressures applicable in the ISM. Further quantification of both gas-phase and solid phase routes through laboratory experiments is needed. Recent laboratory experiments by Fedoseev et al. (2015) do not find $\mathrm{NH}_{2} \mathrm{CHO}$ production in $\mathrm{H}$ - and $\mathrm{N}$-atom bombardment studies of solid $\mathrm{CO}$, consistent with a large barrier for $\mathrm{H}$ - addition to $\mathrm{HNCO}$ found in ab initio calculations (Nguyen et al. 1996), so perhaps the efficiency of this route has been overestimated in the models. An alternative solution would be that the high-mass sources studied here have not gone through a long (pre-stellar) phase in which the dust temperature was low enough for $\mathrm{CO}$ to be frozen out and turned into other molecules.

\section{3. $\mathrm{CH}_{3} \mathrm{CN}$}

The clear mismatches between theory and observations for the ratios involving $\mathrm{CH}_{3} \mathrm{CN}$ point toward an underproduction of acetonitrile by more than an order of magnitude in the models. As with formamide, gas-phase, radical and atom addition reactions contribute to the formation of $\mathrm{CH}_{3} \mathrm{CN}$ in the models, making it difficult to determine the cause. The main formation route in the models by radical addition of solid $\mathrm{CH}_{3}^{\bullet}$ and solid $\mathrm{CN}^{\bullet}$ has never experimentally been investigated. It would therefore be useful to determine if this is a viable solid state formation route and if it potentially has a higher efficiency than assumed.

Alternatively it is possible that photodestruction of solid acetonitrile is not as efficient as assumed in the models. Gratier et al. (2013) find high gas-phase $\mathrm{CH}_{3} \mathrm{CN}$ abundances in the Horsehead PDR, indicative of a high photodesorption rate and slow destruction of $\mathrm{CH}_{3} \mathrm{CN}$ in the ice. Bernstein et al. (2004) indeed find slower photolysis of solid $\mathrm{CH}_{3} \mathrm{CN}$ compared with other organic molecules. If such a slower photodissociation rate would also hold for gas-phase $\mathrm{CH}_{3} \mathrm{CN}$, it would be an attractive explanation why the $\mathrm{CH}_{3} \mathrm{CN}$ rotational temperatures are generally higher than those of other complex molecules (e.g., Bisschop et al. (2007) and many other hot core studies), since the molecule could then approach the protostar closer before being destroyed. However, the gas phase photoabsorption cross sections of $\mathrm{CH}_{3} \mathrm{CN}$ are well determined and if the bulk of these 
absorptions lead to dissociation this would result in a photodissociation rate of gaseous $\mathrm{CH}_{3} \mathrm{CN}$ at least as fast as that of $\mathrm{CH}_{3} \mathrm{OH}$ (van Dishoeck et al. 2006).

Another important parameter for all molecules studied here is the mobility of radicals and neutral molecules on the surface assumed in the gas-grain models. For many species no experimental data are available on diffusion barriers, only theoretically-inspired guesses. Observational evidence suggests that at least parts of the ice mantles are segregated in CO-rich and CO-poor layers (Tielens et al. 1991; Pontoppidan et al. 2008). Therefore, more knowledge of the structure of ice mantles and the mobility of radicals and neutral molecules as a function of surface temperature and in various chemical environments is necessary to determine if addition reactions are likely to happen and at which rates.

\subsection{Prospects for ALMA}

In the near future, much deeper searches for $\mathrm{CH}_{3} \mathrm{NH}_{2}$ can be carried out by ALMA (Appendix B). Figure B.1 shows that the strongest transitions within Band 6 are mainly located between 240 and $275 \mathrm{GHz}$ and in Band 7 around 310, 340 and $355 \mathrm{GHz}$. In Table B.1 the strongest transitions in ALMA's Band 6 and 7 are listed. It becomes apparent that lines covered by Band 7 are more intense, but at the cost of a lower line density.

Estimates done for the W 33A source with the CASSIS line analysis software and the ALMA Sensitivity Calculator show that ALMA should be able to reach the $3 \sigma$ detection limits for the $\mathrm{CH}_{3} \mathrm{NH}_{2}$ lines around $236 \mathrm{GHz}$ in less than $1 \mathrm{~h}$ of integration time, assuming the column density for methylamine of $1.2 \times 10^{14} \mathrm{~cm}^{-2}$ as found by Turner (1991) in a large beam and two orders of magnitude lower than those inferred here for a small source size. This estimate assumes a spectral resolution of $0.64 \mathrm{~km} \mathrm{~s}^{-1}$ as used in our JCMT data, the number of ALMA antennas set to 34 (as in Cycle 2) and a synthesized beam of 1.1", appropriate for the $\mathrm{W} 33 \mathrm{~A}$ hot core (100 K radius).

\section{Conclusions}

We have analysed nine hot core regions in search of methylamine. The molecule has not been convincingly detected, so upper limit abundances are determined for all the sources. From these limits, ratios of methylamine to other molecules $\left(\mathrm{NH}_{2} \mathrm{CHO}, \mathrm{CH}_{3} \mathrm{OH}, \mathrm{CH}_{3} \mathrm{CN}\right)$ have been determined and compared with theory and Sagittarius B2 surveys. Our conclusions are as follows:

1. Trends in our results indicate that both methylamine and formamide are overproduced in the models of Garrod et al. (2008). Acetonitrile is underproduced with respect to these models. This is especially true for the slow models.

2. Abundance ratios do not differ more than an order of magnitude between various sources suggesting that the (nitrogen) chemistry is very similar between hot cores, as has been found previously for other species.

3. More (laboratory) studies are needed to clarify the formation pathway of methylamine and to determine differences and similarities with formamide, methanimine and, to a lesser extent, acetonitrile formation.

4. The upper limits determined for $\mathrm{CH}_{3} \mathrm{NH}_{2}$ here can guide future more sensitive observations, especially with ALMA.
Based on the ratios found in the Sgr B2 observations it is very likely that ALMA will reach the detection limit for methylamine in the sources studied here. Particularly strong transitions and spectral regions to target with ALMA are given.

Acknowledgements. We would like to thank C. Walsh, I. San Jose García, M. Drozdovskaya, N. van der Marel, M. Kama, M. Persson, J. Mottram, G. Fedoseev, M. H. D. van der Wiel and H. Linnartz for their support and input on this project. Thoughtful comments by the referee are much appreciated. Astrochemistry in Leiden is supported by the Netherlands Research School for Astronomy (NOVA), by a Royal Netherlands Academy of Arts and Sciences (KNAW) professor prize, and by the European Union A-ERC grant 291141 CHEMPLAN

\section{References}

Belloche, A., Müller, H. S. P., Menten, K. M., Schilke, P., \& Comito, C. 2013, A\&A, 559, A47

Bernstein, M. P., Ashbourn, S. F. M., Sandford, S. A., \& Allamandola, L. J. 2004, ApJ, 601, 365

Bisschop, S. E., Jørgensen, J. K., van Dishoeck, E. F., \& de Wachter, E. B. M. 2007, A\&A, 465, 913

Blake, G. A., Sutton, E. C., Masson, C. R., \& Phillips, T. G. 1987, ApJ, 315, 621 Burgdorf, M., Cruikshank, D. P., Dalle Ore, C. M., et al. 2010, ApJ, 718, L53

Caselli, P., \& Ceccarelli, C. 2012, A\&ARv., 20, 56

Crockett, N. R., Bergin, E. A., Neill, J. L., et al. 2014, ApJ, 787, 112

Demyk, K., Dartois, E., D’Hendecourt, L., et al. 1998, A\&A, 339, 553

Ehrenfreund, P., \& Charnley, S. B. 2000, ARA\&A, 38, 427

Fedoseev, G., Ioppolo, S., Zhao, D., Lamberts, T., \& Linnartz, H. 2015, MNRAS, 446, 439

Fontani, F., Pascucci, I., Caselli, P., et al. 2007, A\&A, 470, 639

Fourikis, N., Takagi, K., \& Morimoto, M. 1974, ApJ, 191, L139

Garrod, R. T., \& Herbst, E. 2006, A\&A, 457, 927

Garrod, R. T., Weaver, S. L. W., \& Herbst, E. 2008, ApJ, 682, 283

Gibb, E. L., Whittet, D. C. B., Schutte, W. A., et al. 2000, ApJ, 536, 347

Gratier, P., Pety, J., Guzmán, V., et al. 2013, A\&A, 557, A101

Grim, R., Schutte, W., Schmitt, B., \& Greenberg, M. 1989, in Interstellar Dust, eds. L. J. Allamandola, \& A. G. G. M. Tielens, IAU Symp., 135, 245

Halfen, D. T., Ilyushin, V., \& Ziurys, L. M. 2011, ApJ, 743, 60

Halfen, D. T., Ilyushin, V. V., \& Ziurys, L. M. 2013, ApJ, 767, 66

Herbst, E., \& van Dishoeck, E. F. 2009, ARA\&A, 47, 427

Hubbard, J., Voecks, G., Hobby, G., et al. 1975, J. Mol. Evol., 5, 223

Isokoski, K., Bottinelli, S., \& van Dishoeck, E. F. 2013, A\&A, 554, A100

Jones, B. M., Bennett, C. J., \& Kaiser, R. I. 2011, ApJ, 734, 78

Kaifu, N., Morimoto, M., Nagane, K., et al. 1974, ApJ, 191, L135

Maret, S., Hily-Blant, P., Pety, J., Bardeau, S., \& Reynier, E. 2011, A\&A, 526, A47

Neill, J. L., Bergin, E. A., Lis, D. C., et al. 2014, ApJ, 789, 8

Nguyen, M. T., Sengupta, D., Vereecken, L., Peeters, J., \& Vanquickenborne, L. G. 1996, J. Phys. Chem., 100, 1615

Nummelin, A., Bergman, P., Hjalmarson, Å., et al. 1998, ApJS, 117, 427

Nummelin, A., Bergman, P., Hjalmarson, Å., et al. 2000, ApJS, 128, 213

Öberg, K. I. 2009, Ph.D. Thesis, Leiden Observatory, Leiden University, Leiden, The Netherlands

Pickett, H. M., Poynter, R. L., Cohen, E. A., et al. 1998, J. Quant. Spectr. Rad. Transf., 60, 883

Pontoppidan, K. M., Boogert, A. C. A., Fraser, H. J., et al. 2008, ApJ, 678, 1005

Rathborne, J. M., Jackson, J. M., Zhang, Q., \& Simon, R. 2008, ApJ, 689, 1141

Schilke, P., Groesbeck, T. D., Blake, G. A., \& Phillips, T. G. 1997, ApJS, 108, 301

Sutton, E. C., Peng, R., Danchi, W. C., et al. 1995, ApJS, 97, 455

Theule, P., Borget, F., Mispelaer, F., et al. 2011, A\&A, 534, A64

Tielens, A. G. G. M., \& Charnley, S. B. 1997, Origins of Life and Evolution of the Biosphere, 27, 23

Tielens, A. G. G. M., Tokunaga, A. T., Geballe, T. R., \& Baas, F. 1991, ApJ, 381, 181

Turner, B. E. 1991, ApJS, 76, 617

van Dishoeck, E. F., \& Blake, G. A. 1998, ARA\&A, 36, 317

van Dishoeck, E. F., Jonkheid, B., \& van Hemert, M. C. 2006, Faraday Discussions, 133, 231

Walmsley, C. M. 1992, in Chemistry and Spectroscopy of Interstellar Molecules, ed. D. K. Bohme, 267

Walsh, C., Millar, T. J., Nomura, H., et al. 2014, A\&A, 563, A33

Pages 8 to 11 are available in the electronic edition of the journal at http://www . aanda.org 


\section{Appendix A: Methylamine and other transitions}

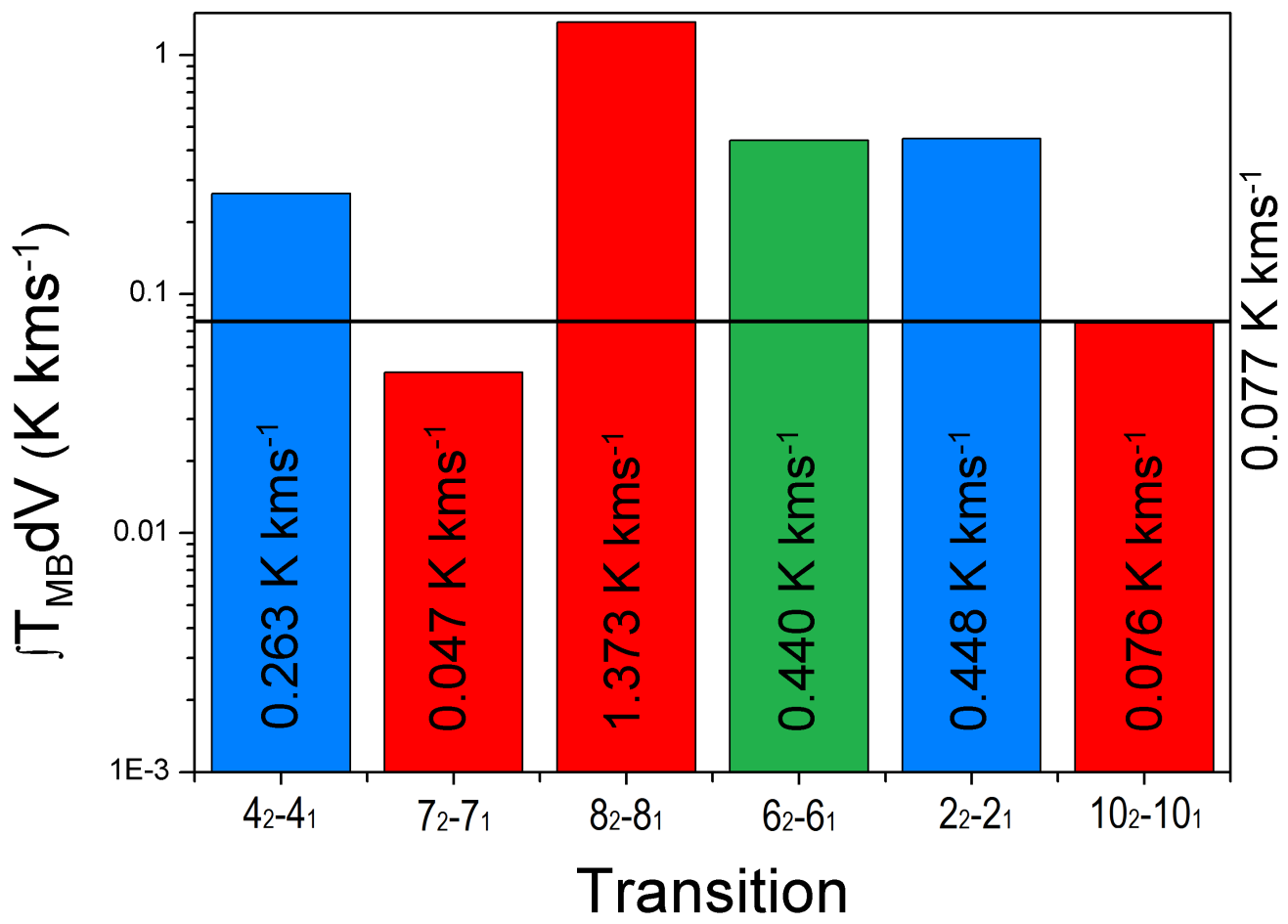

Fig. A.1. Bargraph plot of the integrated main-beam intensities for the six investigated methylamine transitions. $\int T_{\mathrm{MB}} \mathrm{d} V$ values were calculated for a total column density of $3.4 \times 10^{17} \mathrm{~cm}^{-2}$ as inferred toward G31.41+0.31 from the $6_{2} \rightarrow 6_{1}$ transition, assuming a rotational temperature of $120 \mathrm{~K}$. The horizontal line shows the $0.077 \mathrm{~K} \mathrm{~km} \mathrm{~s}^{-1} 3 \sigma$ value for G31.41+0.31. It is unlikely that the detection of the 236408 feature (green) in this hot core is methylamine, since the main-beam intensities of other $\mathrm{CH}_{3} \mathrm{NH}_{2}$ transitions are above the $3 \sigma$ value. Particularly the $4_{2} \rightarrow 4_{1}$ and $2_{2} \rightarrow 2_{1}$ transition (blue) should be visible in our spectra. The remaining transitions (red) are either below detection limit or not observed toward this source. 
N. F. W. Ligterink et al.: Search for methylamine in high mass hot cores

Table A.1. All identified transitions for the sources $\mathrm{G} 31.41+0.31$ and $\mathrm{W} 3\left(\mathrm{H}_{2} \mathrm{O}\right)$, with integrated peak area listed.

\begin{tabular}{|c|c|c|c|c|c|c|}
\hline Species & $\begin{array}{l}\text { Freq. } \\
(\mathrm{MHz})\end{array}$ & $\begin{array}{l}E_{\mathrm{up}} \\
(\mathrm{K})\end{array}$ & $\begin{array}{r}A \\
\left(\mathrm{~s}^{-1}\right)\end{array}$ & Transition & $\begin{array}{r}\mathrm{G} 31.41+0.31 \\
\left(\mathrm{~K} \mathrm{~km} \mathrm{~s}^{-1}\right)\end{array}$ & $\begin{array}{r}\mathrm{W} 3\left(\mathrm{H}_{2} \mathrm{O}\right) \\
\left(\mathrm{K} \mathrm{km} \mathrm{s}^{-1}\right)\end{array}$ \\
\hline $\mathrm{CH}_{3} \mathrm{OCHO}$ & 228628.876 & 118.8 & $1.66 \mathrm{E}-04$ & $18_{5132} \rightarrow 17_{5122}$ & - & 0.39 \\
\hline $\mathrm{CH}_{3} \mathrm{OCHO}$ & 228651.404 & 118.8 & $1.66 \mathrm{E}-04$ & $18_{5130} \rightarrow 17_{5120}$ & - & 0.53 \\
\hline $\mathrm{CH}_{3} \mathrm{COCH}_{3}$ & 228668.358 & 85.4 & $1.69 \mathrm{E}-04$ & $14_{961} \rightarrow 13_{852}$ & - & 0.24 \\
\hline $\mathrm{CH}_{3} \mathrm{OCHO}$ & 229388.947 & 217.0 & $1.62 \mathrm{E}-05$ & $23_{9150} \rightarrow 23_{8160}$ & 0.79 & - \\
\hline $\mathrm{CH}_{3} \mathrm{OCHO}$ & 229405.021 & 110.7 & $1.75 \mathrm{E}-04$ & $18_{3152} \rightarrow 17_{3142}$ & 2.18 & 0.78 \\
\hline $\mathrm{CH}_{3} \mathrm{OCHO}$ & 229420.342 & 110.7 & $1.75 \mathrm{E}-04$ & $18_{3150} \rightarrow 23_{3140}$ & 1.86 & 0.71 \\
\hline $\mathrm{CH}_{3} \mathrm{OCHO}$ & 229504.724 & 134.3 & $1.18 \mathrm{E}-05$ & $20_{3170} \rightarrow 19_{4160}$ & 1.52 & - \\
\hline $\mathrm{CH}_{3} \mathrm{OH}$ & 229589.056 & 374.4 & $2.08 \mathrm{E}-05$ & $15_{40} \rightarrow 16_{30}$ & 2.58 & 1.06 \\
\hline $\mathrm{CH}_{3} \mathrm{OH}$ & 229758.756 & 89.1 & 4.19E-05 & $8_{10} \rightarrow 7_{00}$ & 7.17 & - \\
\hline $\mathrm{CH}_{3} \mathrm{OCHO}$ & 236355.948 & 128.0 & $1.93 \mathrm{E}-04$ & $20_{3181} \rightarrow 19_{3171}$ & 2.38 & - \\
\hline $\mathrm{CH}_{3} \mathrm{OCHO}$ & 236365.574 & 128.0 & $1.93 \mathrm{E}-04$ & $20_{3180} \rightarrow 19_{3170}$ & 1.93 & - \\
\hline $\mathrm{CH}_{3} \mathrm{NH}_{2}$ & 236408.788 & 60.8 & $5.94 \mathrm{E}-05$ & $6_{21} \rightarrow 6_{10}$ & 0.44 & - \\
\hline $\mathrm{HCCCN}$ & 236512.777 & 153.2 & $1.05 \mathrm{E}-03$ & $26 \rightarrow 25$ & 4.67 & 2.27 \\
\hline $\mathrm{H}_{2} \mathrm{CS}$ & 236726.770 & 58.6 & $1.91 \mathrm{E}-04$ & $7_{17} \rightarrow 6_{16}$ & 7.54 & 5.75 \\
\hline $\mathrm{CH}_{3} \mathrm{OCHO}$ & 236743.697 & 129.6 & $1.86 \mathrm{E}-04$ & $19_{5151} \rightarrow 18_{5141}$ & 2.21 & $?^{a}$ \\
\hline $\mathrm{CH}_{3} \mathrm{OCHO}$ & 236759.687 & 129.6 & $1.86 \mathrm{E}-04$ & $19_{5150} \rightarrow 18_{5140}$ & 1.40 & 0.53 \\
\hline $\mathrm{CH}_{3} \mathrm{OCHO}$ & 236800.589 & 136.7 & $1.80 \mathrm{E}-04$ & $19_{6141} \rightarrow 18_{6131}$ & 1.21 & $?$ \\
\hline $\mathrm{CH}_{3} \mathrm{OCHO}$ & 236810.314 & 136.7 & $1.81 \mathrm{E}-04$ & $19_{6140} \rightarrow 18_{6130}$ & 2.50 & 1.20 \\
\hline $\mathrm{CH}_{3} \mathrm{OH}$ & 236936.089 & 260.2 & $2.79 \mathrm{E}-05$ & $14_{10} \rightarrow 13_{20}$ & 2.74 & 1.91 \\
\hline $\mathrm{CH}_{3} \mathrm{OCHO}$ & 236975.844 & 320.3 & 2.01E-04 & $22_{1224} \rightarrow 21_{1214}$ & 0.86 & 0.33 \\
\hline $\mathrm{CH}_{3} \mathrm{OCHO}$ & 236976.390 & 320.3 & 2.01E-04 & $22_{0225} \rightarrow 21_{0210}$ & 0.86 & 0.33 \\
\hline $\mathrm{CH}_{3} \mathrm{OCHO}$ & 236975.844 & 320.3 & $2.01 \mathrm{E}-04$ & $22_{1224} \rightarrow 21_{1214}$ & 1.19 & 0.52 \\
\hline $\mathrm{CH}_{3} \mathrm{OCHO}$ & 236976.390 & 320.3 & 2.01E-04 & $22_{0225} \rightarrow 21_{0215}$ & 1.19 & 0.52 \\
\hline $\mathrm{CH}_{3} \mathrm{OCH}_{3}$ & 237046.092 & 31.3 & 2.33E-05 & $7_{253} \rightarrow 6_{163}$ & 2.90 & 0.80 \\
\hline $\mathrm{CH}_{3} \mathrm{OCH}_{3}$ & 237046.106 & 31.3 & 2.33E-05 & $7_{252} \rightarrow 6_{162}$ & 2.90 & 0.80 \\
\hline $\mathrm{CH}_{3} \mathrm{OCH}_{3}$ & 237048.797 & 31.3 & 2.32E-05 & $7_{251} \rightarrow 6_{161}$ & 2.90 & 0.80 \\
\hline $\mathrm{CH}_{3} \mathrm{OCH}_{3}$ & 237051.495 & 31.3 & 2.33E-05 & $7_{250} \rightarrow 6_{160}$ & 2.90 & 0.80 \\
\hline $\mathrm{SO}_{2}$ & 237068.870 & 94.0 & $1.14 \mathrm{E}-04$ & $12_{39} \rightarrow 12_{210}$ & 1.07 & 1.96 \\
\hline $\mathrm{OC}^{34} \mathrm{~S}$ & 237273.635 & 119.6 & $3.88 \mathrm{E}-05$ & $20 \rightarrow 19$ & 1.24 & 0.58 \\
\hline $\mathrm{CH}_{3} \mathrm{OCHO}$ & 237297.482 & 128.0 & $1.95 \mathrm{E}-04$ & $20_{2182} \rightarrow 19_{2172}$ & $?$ & 2.45 \\
\hline $\mathrm{CH}_{3} \mathrm{OCHO}$ & 237309.540 & 131.6 & $1.98 \mathrm{E}-04$ & $21_{2201} \rightarrow 20_{2191}$ & $?$ & 2.45 \\
\hline $\mathrm{CH}_{3} \mathrm{OCHO}$ & 237315.082 & 131.6 & $1.98 \mathrm{E}-04$ & $21_{2200} \rightarrow 20_{2190}$ & $?$ & 2.45 \\
\hline $\mathrm{CH}_{3} \mathrm{OCHO}$ & 237344.870 & 131.6 & $1.98 \mathrm{E}-04$ & $21_{1202} \rightarrow 20_{1192}$ & 3.48 & 1.19 \\
\hline $\mathrm{CH}_{3} \mathrm{OCHO}$ & 237350.386 & 131.6 & $1.98 \mathrm{E}-04$ & $21_{1200} \rightarrow 20_{1190}$ & 3.48 & 1.19 \\
\hline OCS & 243218.040 & 122.6 & $4.18 \mathrm{E}-05$ & $20 \rightarrow 19$ & - & 2.95 \\
\hline $\mathrm{CH}_{3} \mathrm{OCH}_{3}$ & 259982.561 & 226.6 & 7.27E-05 & $20_{5162} \rightarrow 20_{4172}$ & - & 1.54 \\
\hline $\mathrm{CH}_{3} \mathrm{OCH}_{3}$ & 259982.596 & 226.6 & 7.27E-05 & $20_{5163} \rightarrow 20_{4173}$ & - & 1.54 \\
\hline $\mathrm{CH}_{3} \mathrm{OCH}_{3}$ & 259984.480 & 226.6 & 7.27E-05 & $20_{5161} \rightarrow 20_{4171}$ & - & 1.54 \\
\hline $\mathrm{CH}_{3} \mathrm{OCH}_{3}$ & 259982.561 & 226.6 & 7.27E-05 & $20_{5160} \rightarrow 20_{4170}$ & - & 1.54 \\
\hline $\mathrm{NH}_{2} \mathrm{CHO}$ & 260189.848 & 92.4 & $1.25 \mathrm{E}-03$ & $12_{210} \rightarrow 11_{29}$ & - & 1.46 \\
\hline $\mathrm{H}^{13} \mathrm{CO}+$ & 260255.339 & 25.0 & $1.33 \mathrm{E}-03$ & $3 \rightarrow 2$ & - & 11.76 \\
\hline $\mathrm{CH}_{3} \mathrm{OCH}_{3}$ & 260327.165 & 208.3 & $7.21 \mathrm{E}-05$ & $19_{5152} \rightarrow 19_{4162}$ & - & 1.27 \\
\hline $\mathrm{CH}_{3} \mathrm{OCH}_{3}$ & 260327.238 & 208.3 & $7.21 \mathrm{E}-05$ & $19_{5153} \rightarrow 19_{4163}$ & - & 1.27 \\
\hline $\mathrm{CH}_{3} \mathrm{OCH}_{3}$ & 260329.312 & 208.3 & 7.21E-05 & $19_{5151} \rightarrow 19_{4161}$ & - & 1.27 \\
\hline $\mathrm{CH}_{3} \mathrm{OCH}_{3}$ & 260331.422 & 208.3 & 7.21E-05 & $19_{5150} \rightarrow 19_{4160}$ & - & 1.27 \\
\hline $\mathrm{SiO}$ & 260518.020 & 43.8 & $7.21 \mathrm{E}-05$ & $6 \rightarrow 5$ & - & 9.24 \\
\hline
\end{tabular}

Notes. ${ }^{(a)}$ Identified transition where it was not possible to determine the peak area. 


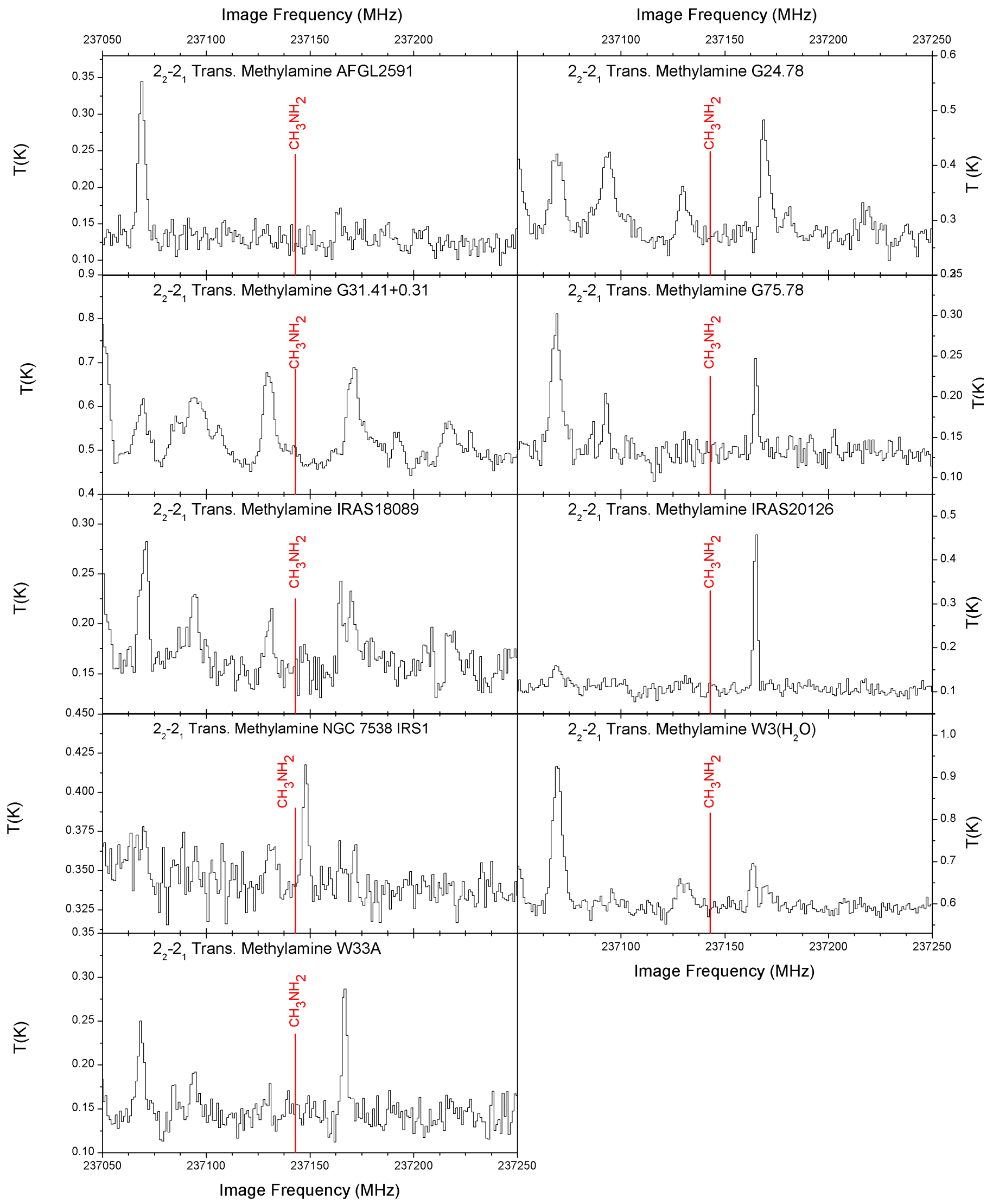

Fig. A.2. Blow-up of the spectral region around the $2_{2} \rightarrow 2_{1}$ transition at $237143 \mathrm{MHz}$ of all analysed hot cores. Despite being a particularly strong transition, it was not observed in any of the spectra. 


\section{Appendix B: ALMA}

In the following figure the simulated spectrum of methylamine is shown for a column density of $1.0 \times 10^{15} \mathrm{~cm}^{-2}$ at an excitation temperature of $120 \mathrm{~K}$. Simulations were done with CASSIS using the JPL spectroscopic database. The frequency ranges were taken to cover ALMA Bands 6 and 7. The resolution was set at $0.1 \mathrm{MHz}$ for this spectrum.

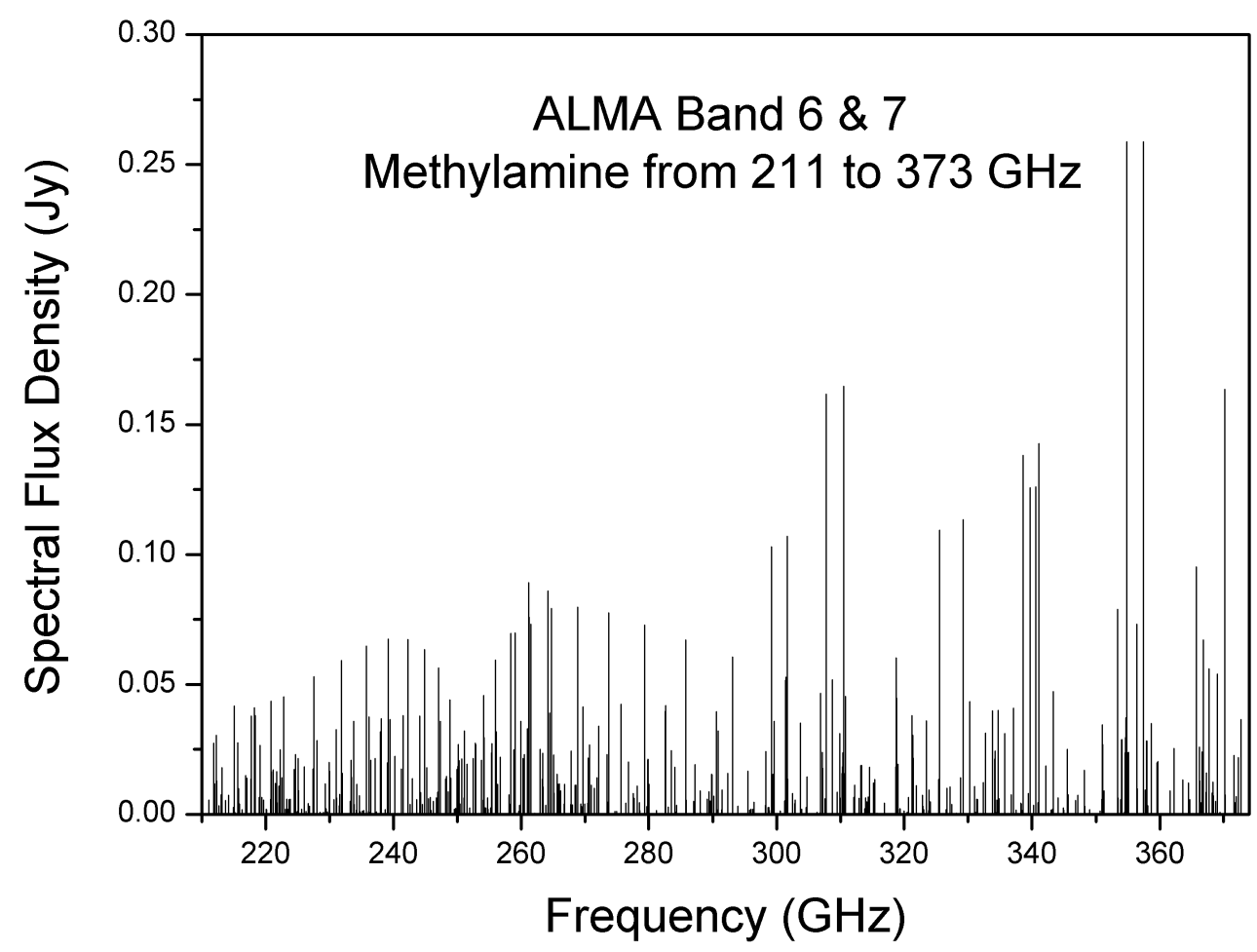

Fig. B.1. 211 to $373 \mathrm{GHz}$ spectrum of methylamine, covering ALMA bands 6 and 7. A column density of $10^{15} \mathrm{~cm}^{-2}, T_{\text {rot }}$ and beam size of $1^{\prime \prime}$ are used.

Table B.1. Methylamine transition target candidates for ALMA Band 6 and 7.

\begin{tabular}{ccrc}
\hline \hline Transition & $\begin{array}{c}\text { Freq. } \\
(\mathrm{MHz})\end{array}$ & $\begin{array}{r}E_{\text {up }} \\
(\mathrm{K})\end{array}$ & $\begin{array}{c}A \\
\left(\mathrm{~s}^{-1}\right)\end{array}$ \\
\hline $7_{26} \rightarrow 7_{16}$ & 227498.06 & 75.4 & $4.80 \mathrm{E}-05$ \\
$5_{2} \rightarrow 5_{16}$ & 232003.95 & 47.7 & $4.73 \mathrm{E}-05$ \\
$8_{23} \rightarrow 8_{12}$ & 235735.04 & 92.8 & $6.13 \mathrm{E}-05$ \\
$7_{22} \rightarrow 7_{13}$ & 239209.63 & 75.8 & $6.29 \mathrm{E}-05$ \\
$6_{23} \rightarrow 6_{12}$ & 242262.02 & 60.9 & $6.39 \mathrm{E}-05$ \\
$5_{22} \rightarrow 5_{13}$ & 244886.90 & 48.1 & $6.42 \mathrm{E}-05$ \\
$8_{05} \rightarrow 7_{15}$ & 259042.46 & 77.0 & $5.73 \mathrm{E}-05$ \\
$6_{22} \rightarrow 6_{13}$ & 261252.89 & 60.9 & $7.14 \mathrm{E}-05$ \\
$8_{02} \rightarrow 7_{13}$ & 261563.15 & 76.8 & $5.98 \mathrm{E}-05$ \\
$4_{15} \rightarrow 3_{05}$ & 264172.21 & 25.9 & $8.74 \mathrm{E}-05$ \\
$8_{22} \rightarrow 8_{13}$ & 268898.14 & 92.8 & $7.44 \mathrm{E}-05$ \\
$9_{05} \rightarrow 8_{15}$ & 299189.80 & 96.1 & $8.78 \mathrm{E}-05$ \\
$9_{03} \rightarrow 8_{12}$ & 301654091 & 95.9 & $9.11 \mathrm{E}-05$ \\
$5_{-13} \rightarrow 4_{02}$ & 307791.75 & 36.3 & $1.44 \mathrm{E}-04$ \\
$14_{22} \rightarrow 14_{-13}$ & 310750.84 & 240.0 & $8.33 \mathrm{E}-05$ \\
$10_{05} \rightarrow 9_{15}$ & 338628.32 & 117.3 & $1.25 \mathrm{E}-04$ \\
$10_{02} \rightarrow 9_{-13}$ & 341059.48 & 117.1 & $1.30 \mathrm{E}-04$ \\
$6_{12} \rightarrow 5_{03}$ & 354843.73 & 49.2 & $2.16 \mathrm{E}-04$ \\
$6_{15} \rightarrow 5_{05}$ & 357440.12 & 49.5 & $2.16 \mathrm{E}-04$ \\
$3_{24} \rightarrow 2_{14}$ & 370166.34 & 28.4 & $2.11 \mathrm{E}-04$ \\
\hline
\end{tabular}

